\title{
Irmgard Bartenieff: uma herança de conectividade
}

Irmgard Bartenieff: an inheritance of connectivity

Marisa Martins Lambert ${ }^{1}$

\section{RESUMO}

Ao evidenciar a trajetória da educadora somática e pesquisadora do movimento Irmgard Bartenieff, este artigo busca deixar aparente o fluxo entre aspectos singulares e dimensões coletivas que sublinharam a configuração dos conceitos e princípios de seu método, "Fundamentos Corporais do Movimento". Releva a percepção peculiar de Bartenieff sobre a mobilidade do corpo, aborda sua ideia de "conectividade" em inter-relação com sua leitura ampliada e flexível sobre a ação artística e a expressividade corporal do sujeito no mundo.

Palavras-chave: Irmgard Bartenieff. Conectividade. Fluxo singular/coletivo.

\section{ABSTRACT}

By highlighting the trajectory of the somatic educator and the movement researcher Irmgard Bartenieff, this paper seeks to make apparent the flow between singular aspects and collective dimensions that underlined the configuration of the concepts and principles of her method, "Movement Fundamentals". It points out Bartenieff's peculiar perception of the body mobility and addresses her idea of "connectivity" in interrelation to her expanded and flexible reading of the artistic action and the one's body expressivity in the world.

Keywords: Irmgard Bartenieff. Connectivity. Singular/collective flux.
1.

Professora do Programa de Pós-Graduação em Artes da Cena e do Departamento de Artes Corporais da Universidade Estadual de Campinas (Unicamp). Contato: marisalambert@iar.unicamp.br ORCID: http://orcid.org/ 0000-0002-3392-6833

Submetido em: 28/11/2016, aceito em: 09/12/2016. 
O principal objetivo de todo este material está em sugerir modos adicionais de perceber a si próprio e o mundo ao seu redor, utilizando seu corpo vivo totalmente - corpo/mente/sentimentos - como uma chave para lidar positivamente com o meio ambiente. [...] O coração para esta 'vida plena' é o movimento e, portanto, é o próprio movimento que temos estudado. Como o seu corpo funciona em movimento - corpo/ esforço/forma - e o que isto significa para a sua percepção e expressão

(Irmgard Bartenieff).

O maior escrito deixado pela educadora somática, pesquisadora, analista do movimento e bailarina Irmgard Bartenieff, seu livro "Body Movement: Coping with the environment", coescrito com Doris Lewis e publicado em 1980, apresenta várias de suas ideias sobre organização corporal, suporte para o movimento e expressividade. Porém, como já anuncia o título da publicação, ao expor seus princípios e conceitos tensiona questões que emergem do dialogo móvel, de troca e comunicação, entre indivíduo e meio, enfatizando que o propósito de se investigar a mobilidade não finda nas fronteiras do reconhecimento de "si mesmo", mas se completa na interação com o espaço, com o outro, na criação de redes com o coletivo.

Interligado às teorias de Rudolf Laban² (1879-1958), o material elaborado por Bartenieff também aproxima o movimento humano de uma leitura em fluxo de suas diversas variantes e componentes. Isto é, compreende os temas e elementos constituintes da linguagem do corpo em movimento, não de forma isolada, mas em relações de continuidade, que borram e friccionam definições de sentidos, renovando incessantemente seus significados. Quem se aprofunda nos conteúdos abordados por esses pesquisadores, hoje divulgados em conjunto pelo Laban/Bartenieff Institute of Movement Studies, Nova Iorque, USA, vai alargar sua perspectiva de observação e entendimento de processos relacionais como corpo/mente, corpo/ espaço, interno/externo, percepção/ação, ação/recuperação, função/expressão (para citar apenas alguns), passando a compreendê-los no acontecimento do movimento como princípios com características ao mesmo tempo polares mas complementares, em constante fluxo de tornar-se um o outro.

Neste artigo traremos um olhar para processos de continuidade que atravessam a constituição propriamente dita do método somático de Irmgard Bartenieff, procurando iluminar enlaces que se estabelecem entre experiências de singularidade e coletividade, vistas enquanto dimensões de um mesmo fenômeno que refletem nossa dinâmica de movimento e vida em constante transmutação. Enfocaremos o percurso singular de Bartenieff, sua história pessoal, para chegar à formulação de sua visão de corpo e movimento, expressa em seus conceitos, apontando como
2. Rudolf von Laban, teórico, coreógrafo e renomado pesquisador do processo do movimento, desenvolveu, na Europa expressionista da primeira metade do século $\mathrm{XX}$, um complexo sistema de experimentação, leitura interpretação da linguagem do corpo. Suas proposições atravessaram o tempo e vêm fornecendo, ainda hoje, amplo material para artistas, educadores corporais e investigadores de diversas áreas de conhecimento. 
esses já se modulam a partir de referências do coletivo - afirmações sobre os fundamentos do movimento humano - e, em igual medida, como a construção da mobilidade de cada sujeito, seja ela com função cotidiana ou artística, se amplia por relações de alteridade ou no encontro e intersecção com o ambiente.

\section{O circuito dentro/fora de Irmgard Bartenieff}

Para compreender a raiz de inspiração e o propósito que motivou a configuração do método "Fundamentos Corporais do Movimento" de Bartenieff, sugiro, primeiramente, aproximarmo-nos da pessoa que o concebeu - de sua natureza individual e sua trajetória contextual de formação e informação. Falar sobre Bartenieff ${ }^{3}$ envolve embrenhar-se no contínuo questionamento sobre o sentido do termo "conectividade". Conectar-se via movimento é a expressão primeira da disposição que temos de nos vincularmos ao mundo, de conhecer o outro e comunicar quem somos (BARTENIEFF, 1980). Uma função que se desdobra do próprio processo de aprendizado neuro-sensório-motor, intrínseco aos seres humanos. Refere-se à maneira, ao mesmo tempo singular e universal (compartilhada por todos), de sustentar nossa intenção no trânsito interno/externo, de transmitir nossas ideias, projetos, ou pontos de vista, criando elos, cada vez mais complexos e criativos, entre aquilo que está dentro e fora de nós mesmos. A ação de conectar-se possibilita que o espaço interno do corpo atravesse em direção ao externo, experiência, portanto, que transcende limites e dissolve fronteiras.

Ainda, em sua visão, para que se efetive um processo de conexão, precisamos começar "em casa", no nosso próprio corpo. O reconhecimento de si é saber fundante para que a relação sujeito-mundo floresça, incorpore fluência e qualidades, e se projete na conquista de completude expressiva e comunicação. Seguindo o mesmo impulso que Laban, Bartenieff sugeriu-nos olhar para o movimento como a pedra de base de todo conhecimento, patamar para a construção de identidade e alicerce para a atividade humana; movimento que, quando integrado em suas funções, mentais, físicas, emocionais e existenciais, enriquece e amplia a vida, potencializando tanto as experiências de singularidade, em seus aspectos subjetivos e expressivos, quanto a criação de tramas de conectividade que eclodem da escuta e participação nas esferas coletivas.

Irmgard Bartenieff nasceu em Berlim, Alemanha, em 1900. Viveu sua juventude na Europa, onde estudou história da arte antiga ${ }^{4}$, música e dança. Unindo seu interesse em tornar-se coreógrafa ao seu contato com formas variadas de expressão,
3.

Trechos desse artigo foram anteriormente discutidos no capítulo "Bartenieff, a Dança e os Processos Somáticos de Percepção, Contato e Intenção Espacial", de minha autoria, como parte do livro "Coleção Corpo em Cena" (RENGEL; THRAIL, 2013).
4.

Seu marido, Michail Bartenieff, era pesquisador e professor de história antiga na Universidade de Munique. Bartenieff viajou com ele várias vezes para Grécia e Itália, onde se alimentou com uma grande diversidade de criações artísticas. Estudou em Munique conceitos sobre como se reconhecer uma obra, proporções, relações espaciais, cores, formas, mas consciente de que, como mencionam os gregos, "[...] the human being is the mesuare of everything" (SIEGEL, 1980, p. 4). 
desenvolveu uma maneira particular de filtrar informações pela observação das relações móveis entre os elementos da arte. Com olhar arraigado à percepção do movimento, "protestava contra falar apenas sobre 'estilo' e preferia falar sobre a forma como as composições eram apresentadas. [...] [tinha um olhar] que vinha junto com um sentido de movimento" (BARTENIEFF, apud SIEGEL, 1980, p. 3). Desde seu primeiro contato com Laban, em 1925, foi fortemente instigada por suas ideias, tendo testemunhado o desenvolvimento de suas teorias. Estudou com vários membros da sua primeira geração de seguidores ${ }^{5}$, aprimorando-se nas áreas de conhecimento já então esboçadas por ele - notação do movimento (então conhecida como Kinetografia Laban), Harmonia do Espaço (Corêutica), Eucinética (que depois abarcou a teoria dos esforços) e Dança Coral $^{6}$. De 1929 a 1933, realizou trabalhos artísticos com a companhia "Romantiches Tanztheatre Bartenieff", criada por ela e seu marido, Michail Bartenieff, colocando em prática sua visão peculiar da dança de seu tempo. "Suas próprias coreografias tinham uma tendência em direção a temas românticos e histórias poéticas" (FEARS, s/d) 7 , com interferência, em sua concepção, das novas proposições moderno-expressionistas que se instalavam na Europa.

Bartenieff deu andamento a seus próprios interesses de estudo sobre a linguagem do movimento, embasada na investigação do material de Laban. Segundo ela (1980, p. 4), os estudos de Laban foram, desde o início, um ponto de referência de extrema importância para sua compreensão do processo do movimento, por não ser uma ferramenta de função puramente objetiva, e sim uma filosofia, um alargamento e um refinamento de percepção; ideias e teorias que é preciso, à maneira de cada um, unir em conjuntos diversos.

Nesse período de formação, também se manteve consciente e em contato com o surgimento de linhas de trabalho corporal que propunham exercícios de sensibilização e consciência cinética para o estudo do funcionamento do corpo e reabilitação postural. Em um de seus manuscritos, comenta sobre o desenvolvimento de técnicas de trabalho corporal que se desenvolviam na Europa e Estados Unidos por volta da década de 1920: métodos de consciência do corpo baseados na concentração mental, uso de imagens e percepção exploratória, como de Charlotte Selder, Mathias Alexander, Mabel Todd, Lulu Sweigard; e métodos considerados por ela mais cinesiológicos e voltados para o movimento e ação no ambiente, como de Moshe Feldendrais, Gerda Alexander e Rudolf Laban (BARTENIEFF, 1977).

O confronto com esses pensamentos e as vivências com as artes e a dança constituíram uma primeira camada de atraves-
5

Entre 1925-27, Bartenieff estudou Corêutica com Gertrude Loesser, Eucinética com Dussia Bereska (com quem desenvolveu uma relação bastante próxima) e notação com Albert Knust, mais tarde seu parceiro na tradução de peças coreográficas em Kinetografia Laban.

6.

Dança Coral é um modo de composição coreográfica executado por um grande número de participantes, com movimentações inspiradas em gestos do cotidiano, "[...] que buscava um sentido coletivo e comunitário, festivo, criativo e terapêutico"

(RENGEL, 2001, p. 83). Como exemplos, Laban dirigiu uma dança coral com 500 participantes para o Festival de Mannhein e coreografou uma gigantesca composição em Viena, utilizando 10.000 participantes (FEARS, s/d).

7 .

Informações coletadas de material didático fornecido pelo Programa Laban/Bartenieff de Análise do Movimento 1994-1996, Montreal, CA.: FEARS, E. W. A short chronological biography of Irmgard Bartenieff. New York: Institut Laban/Bartenieff of movement analisys, sem data. 
samentos externos, engajamentos com motivações coletivas, vínculos com outros, principalmente Laban, que contribuíram para afirmar a visão de corpo e ação artística de Bartenieff em desenvolvimento no período entre guerras europeu. Em um mundo, portanto, cabe aqui acrescentar pela perspectiva de hoje, que passa a se sustentar por referências contextuais em constante mutação, e no qual o corpo vai gradativamente (no decorrer das décadas do século XX) ser evocado a assumir um lugar mais versátil, de contato sensível consigo e criador de sua própria paleta expressiva, na interface com o meio (SUQUET, 2008).

Como tantos outros artistas, estudiosos e cientistas, em 1936, em consequência das pressões nazistas, Bartenieff deixa a Alemanha e muda-se para a América do Norte. Em Nova Iorque, alarga seu campo de atuação. Estuda fisioterapia e massagem no "Swedish Institute of Massage" e, durante a última epidemia de poliomielite, torna-se especialista na reabilitação de pacientes com problemas de mobilidade. "Eu não queria deixar nada (sua pesquisa com a dança e o movimento) de lado. Eu queria ficar com o corpo humano; isto me levou para a terapia corporal" (BARTENIEFF, apud SIEGEL, 1980, p. 5). Essa experiência foi propulsora para o vislumbre de uma maneira inovadora de trabalhar. Bartenieff percebeu, desde o início, que treinamentos físicos baseados puramente em manipulações ou repetição de exercícios mecânicos, focados em áreas individualizadas do corpo, eram insuficientes para se atingir conectividade. Era necessário respeitar o contínuo parte/todo, corpo/espaço. Aproximando seu treinamento Laban de suas considerações sobre os caminhos proprioceptivos e cinesiológicos que estabelecem inter-relações entre sujeito/meio, dá continuidade à investigação do potencial do movimento como motivador de relações mais abrangentes e material para novas aprendizagens sobre a expressão de cada indivíduo e o papel do corpo nas dinâmicas de coletividade.

Na tentativa de religar partes do corpo em coordenação, Bartenieff chega a um importante insight. Propõe olhar para o organismo como um todo; pensar em termos globais - corpo/ mente/ação integrados -, já que o ser humano é único com a cultura, a expressão funcional, o espaço, a energia, a arte, o trabalho, o ambiente, a religião (SIEGEL, 2003). Em outras palavras, sua atitude terapêutica instituiu uma aproximação não apenas lógica de um problema físico, mas valorizou a absorção de uma impressão global da pessoa e a inclusão de todos os seus campos, singulares e coletivos, em sua recuperação. Uma postura que, sem dúvida, cresceu de sua experiência holística com Laban sobre percepção, expressividade e análise do movimento. 
Tomando por base sua vivência na arte e sua prática na área da saúde, conceitos centrais de seu método começaram a se desenvolver: a inclusão do elemento do espaço como estimulador da ação; o uso de diferentes qualidades expressivas para se despertar fluência cinética; a utilização da mobilidade tridimensional como fator de expansão de possibilidades; e, acima de tudo, seu interesse em engajar a singularidade do paciente, corporal e psíquica, como via de reestruturação do movimento, unindo realidades internas à organização do funcionamento do corpo e participação no ambiente. Para ela, vivências que se passam num contexto interno precisavam ser integradas e expandidas, em movimentos amplos, ao mundo externo - sair de dentro e mover-se no espaço de maneira pessoal e qualitativa.

Conceitos espaciais têm que ser incorporados em atividades mecânicas, anatômicas, de forma a produzir máximo funcionamento. Em terapia corporal, isto significa pensar em termos do movimento no espaço ao invés de apenas fortalecer grupos musculares. A introdução de conceitos espaciais requer uma consciência da intenção por parte do paciente que ativa sua vontade e então conecta sua participação independente à sua própria recuperação (BARTENIEFF, 1980, p. 3).

Orientada pelo trânsito percepção/ação, Bartenieff insistia que um processo de reeducação neuromuscular deve encontrar sua resposta de conexão na própria versatilidade do movimento. Reabilitar habilidades não recai apenas em aquecer e treinar músculos por meio de tarefas repetitivas, incidindo sobre o erro do corpo-máquina. É preciso animar a sensibilidade e o desejo da ação; reinvestir na intenção criativa, que é realmente necessária para se continuar refazendo o movimento com consistência, encadeamento e expressividade. "Ativar e Motivar" torna-se o mantra de Irmgard, que veio do seu primeiro professor de terapia corporal, George Deaver, e que depois se transforma em um de seus mais importantes princípios pedagógicos (HACKNEY, 1998, p. 5).

Fica evidente que o olhar de Bartenieff rompe convenções, ao propor o desfazer de uma percepção separatista do sujeito e investir na permeabilidade entre ambientes e funções, alargando a extensão do que o corpo pode ser e alcançar. Suas descobertas vão apoiar-se no entendimento de que a subjetividade de cada um só se desdobra em gesto expressivo - isto é, se desloca de si para promover um discurso no mundo - quando em diálogo com o que provém do ambiente de fora, espaço de todos. Em reverso, aponta que, como revelado no movimento do anel de moebius, é na transposição do que está fora para si, pelo reconhecimento do outro, que se constrói o universo do interno, geram-se autorreferências e desejos criativos. 
Paralelamente à sua atividade em instituições hospitalares, Bartenieff manteve-se em interação com a área da dança. Introduziu Labanotation em Nova Iorque, acolhida pela bailarina Hanya Holm ${ }^{8}$ em seu estúdio e, em Massachussets, deu aulas de dança para crianças e para o público não profissional. A partir de 1950, por cinco verões consecutivos, volta a estudar com Laban e seus colegas na Inglaterra ${ }^{9}$. Bartenieff considerava que os princípios de Laban sobre o corpo, o espaço e as dinâmicas qualitativas eram tão ricos, complexos, interessantes e operativos que permitiam analisar qualquer tipo de movimento:

[...] fazer diferentes seleções quando você quer estudar alguma coisa. Mas primeiro você tem que compreender o todo, para poder fazer seleções. [...] é por isto que sempre falamos sobre o triangulo Corpo, Espaço e Esforço - ou o funcional e o expressivo juntos (BARTENIEFF, apud SIEGEL, 1980, p. J).

Retomando o apresentado, as teorias de Laban e Bartenieff abrangem os elementos da experiência corporal de maneira integrada; interessam-se por escutar o movimento que se produz por um processo de alternância dinâmica entre funções, e mesmo quando se dedicam a compreender ou aprimorar uma especificidade - lidar com um movimento micro ou um padrão singular -, não o olham pelo prisma do isolamento, mas buscam enxergar a imbricação das nuances do espaço interno em relação coextensiva com o contexto externo.

Em uma de suas viagens a Inglaterra, Bartenieff apresentou a primeira forma do que viria a ser os "Fundamentos do Movimento". Trabalhou novamente com Laban, em sessões individuais, pouco antes de sua morte, sentindo-se preenchida com a compreensão das ideias exploradas por ele e desenvolvidas em seu trabalho. De 1950 a 1955, sentindo-se em domínio desses referenciais, estruturou cursos sobre o sistema Effort/ Shape (Esforço/Forma) de análise do movimento, um desenvolvimento das ideias de Laban sobre Corêutica e Eucinética, sistematizados por Warren Lamb ${ }^{10}$. Lecionou também para bailarinos e terapeutas na escola Turtle Bay, em Nova Iorque.

Pelos estudos e desenvolvimento de seus princípios, Bartenieff torna-se ciente das implicações psicológicas do movimento - movimento engendra sentimentos. Busca aprofundamento no conhecimento das inter-relações entre experiências pré-conscientes e conscientes por meio do movimento, nutrindo-se em uma prática ativa com recém-nascidos e crianças e na pesquisa do processo de desenvolvimento neuro-sensório-motor. Constata e afirma que o corpo contém uma sabedoria não acessível por sondagens intelectuais lineares; mover-se, e
8.

Formada pela escola de Mary Wigman em Dresden, a bailarina expressionista alemã Hanya Holm foi convidada para lecionar e codirigir a escola de Wigman. Ambas dividiram um elo especial por meio do movimento. Em 1931, Holm parte para os Estados Unidos para iniciar um braço da escola de Wigman em Nova Iorque, representando seu nome e sua filosofia de ensino. Mais tarde, distanciando-se de suas fontes, seu estúdio passa a ser conhecido com seu nome. Suas habilidades a levaram a desenvolver sua própria forma de técnica, que influenciou vários bailarinos norte-americanos.

9.

Aprofundou seus estudos com a segunda geração de seguidores de Laban: Warren Lamb, Marion North e Valerie Preston-Dunlop. Também conheceu Lisa Ullman, Ann Hutchinson, Kurt Joss, Geraldine Stepherson, entre outros - artistas, educadores e pesquisadores do movimento cujos trabalhos contribuíram muito ao desenvolvimento das teorias de Laban.

10.

O inglês Warren Lamb auxiliou Laban no desenvolvimento das suas teorias sobre perfis de movimento. Criou o método Movement Profiles, uma ferramenta baseada na observação das características de esforço e forma de movimento. Maiores informações ver Davies (2006). 
o desejo de perceber o movimento, traz acesso a um conhecimento corporal que revela a natureza multidimensional das relações entre homens e contexto (HACKNEY, 1998, p. 3).

Ainda, seu interesse pelos Padrões Neurocinesiológicos Básicos ${ }^{11}$ marca a imbricação desse conhecimento no que virá a ser o método "Fundamentos Corporais do Movimento", e a referência do coletivo na composição de seus conceitos. Entendidos como matéria-prima para o processamento das etapas de desenvolvimento características da raça humana mudanças da posição deitada, para o rolamento, modos de arrastar, sentar, engatinhar, transferências de apoio até chegar a posição da caminhada - esses padrões, pautados em informações filogenéticas e ontogenéticas, sublinham uma base universal para a mobilidade, sensibilizando o corpo de toda a sua potencialidade e interligando-o a evolução milenar de sua espécie. A partir desse alicerce, conexões mais complexas, voluntárias e criativas se organizam, configurando as singularidades do movimento próprio. E, uma vez que o aprendizado motor esta conectado ao amadurecimento sensorial, emocional e cognitivo, cada novo padrão incorporado, representa também acesso a um novo ambiente do imaginário, da expressividade e comunicação.

Apropriada desses saberes, Bartenieff é contratada para trabalhar como dança-terapeuta em hospital psiquiátrico ${ }^{12}$, contribuindo para a inauguração de um novo campo de trabalho. Funda a associação de dança-terapia nos Estados Unidos e é reconhecida como uma das pioneiras nessa área de pesquisa em dança.

No estudo do movimento humano, a visão e experiência de Bartenieff ampliam-se sucessivamente, abrangendo questões de ordem funcional, qualitativa, terapêutica, pedagógica, artística e cultural. "Sua geniosidade era sua amplitude, [...] não havia limite para as disciplinas que ela era capaz de compreender e comentar sobre a perspectiva do sistema Laban" (REED, 2003, p. 9). Ao lado de Martha Davis e Forestine Pauley, duas de suas primeiras discípulas, desenvolveram procedimentos de observação do comportamento corporal, fundados nos métodos de análise de Laban e Lamb. Em 1965, instituem o primeiro programa de estudos do movimento - Effort/Shape program -, sediado no Dance Notation Bureau, Nova Iorque. Ainda em parceria com Alan Lomax e Forrestine Paulay, empreendeu um projeto visionário, Choreometrics, pesquisa que correlacionou movimentos de dança e movimentos cotidianos em várias culturas; um estudo ético e de grande respeito à vivência cinética do coletivo.

Como dança-terapeuta e analista do movimento, Bartenieff trabalhou para facilitar mudanças e proporcionar um cresci-
11.

Referem-se à construção de cadeias cinéticas de base, isto é, ativação de caminhos habituais de mobilidade que relacionam as partes do corpo entre si e estas com o espaço. Exemplo: relação de expansão/ recolhimento (pela respiração), centro/extremidade, cabeça/ cóccix, unidade inferior/ unidade superior, padrões homólogos e cruzados.

12.

De 1957 a 1967, Bartenieff atua como pesquisadora assistente no Departamento de Psiquiatria Social do Albert Einstein Medical College, e no Bronx State Hospital, ambos em Nova Iorque. Concomitante, de 1953 a 1962, foi terapeuta-chefe e coordenadora de programa para crianças, no Blythedale Hospital, e estudou desenvolvimento motor no Long Island Juwish Hospital (FEARS, s/d). 
mento do indivíduo por meio do movimento. Buscou, como vem sendo largamente apresentado, promover experiências de movimento em que cada pessoa pudesse descobrir um sentido expandido de si próprio em tessitura com o mundo (RUBENFILD, 1977).

Junto ao público dos artistas da dança, seu trabalho germina como uma proposta de reeducação do movimento, aplicável a qualquer estilo, com expertise em abordar dificuldades posturais, problemas de lesões e tensões musculares, ou questões de origem expressiva. Durante a década de 1960, sua pesquisa ficou conhecida como Correctives, pois evoluiu pela busca de solucionar ineficiências nos caminhos de conectividade, seja em bailarinos, crianças, adultos ou junto ao público portador de necessidades especiais. Ao final dos anos 1960 e início dos 1970, seu trabalho passou a se chamar Fundamentals, momento em que Bartenieff reconheceu que o que fazia não era corrigir o que estava desconecto, mas, sim, reafirmar o que era básico para todos os seres humanos.

Aqueles que conviveram pessoalmente com Bartenieff afirmam que sua maneira de ensinar levava seu grupo de alunos à exploração de novos territórios, que, consequentemente, mudavam suas perspectivas acerca de si e do ambiente (GOLDMAN, 2003, p. 9). Com espírito altamente poético, olhar abrangente e ao mesmo tempo discriminativo, tinha o talento de enxergar o centro de uma temática. No entanto, não procurava teorizar, prendendo esse conhecimento em saberes estáticos, mas, sim, mantinha a experiência de seus alunos focada no movimento e no que está no corpo, sem determinar conquistas pré-definidas sobre aquilo que deveria ser atingido (HACKNEY, 1998; SIEGEL, 2003). Sempre iluminada pela curiosidade, com atitude exploratória e livre de regras específicas, usava ferramentas variadas, dependendo da necessidade do momento uma imagem poética, a respiração, vias proprioceptivas (toque, visualização, massagem), o trabalho com as dinâmicas e frases expressivas, a apresentação de um princípio - em busca de uma resposta completa do corpo: "You use what you find; you do what works" (BARTENIFF, apud SIEGEL, 1980, p. 7).

Por essas razões, a prática dos Fundamentos Corporais do Movimento diferencia-se bastante das formas de treinamento tradicional em dança, baseadas em um tempo específico (contagem métrica), imitação de gestos e movimentos e aspectos técnicos uniformizadores a serem alcançados, que restringem o envolvimento expressivo pessoal. Segundo Hackney (1998) a metodologia de Bartenieff trabalha com princípios e conceitos que sublinham procedimentos de descoberta que se interconectam. E ela complementa, descrevendo, sobre as aulas da mestra, sua profunda experiência de contrastes: 
As aulas de Bartenieff eram cheias de movimentos amplos do corpo inteiro. [...] Nós tomávamos tempo para ir no 'interno'. Nós definitivamente passávamos um tempo no chão, mas então trabalhávamos nos movendo pelo espaço, experimentando mudanças de forma em uma frase, enquanto usávamos nossas vozes para apoio rico dos esforços (HACKNEY, 1998, p. 4).

Seguindo um percurso de pesquisa cada vez mais aprofundada, e visando dar continuidade ao seu trabalho, fundou em 1978 o Instituto Laban/Bartenieff de Estudos do Movimento, Nova York, onde os Fundamentos Corporais do Movimento passam a ser transmitidos em íntima relação com as teorias de Laban. Ao enfatizar uma visão somática do corpo - desenvolvimento da sensibilidade corporal, construção de um guia cinestésico interior, clareza do uso de cadeias motoras e, ainda, o despertar de uma intencionalidade poética unida à projeção do movimento no espaço para além das extremidades do corpo estabelece uma nova categoria de estudos do movimento, redimensionando a amplitude dos conceitos de Laban:

Até que Irmgard Bartenieff trouxesse sua perspectiva de trabalho corporal para as estruturas de Laban, faltava neste trabalho um componente do corpo. Enfatizar a importância das conexões internas do corpo no fazer o movimento, tornar-se vivo dentro do indivíduo e fora no mundo, foi a contribuição singular de Irmgard ao trabalho de Laban (HACKNEY, 1998, p. 1).

Esse olhar sobre o percurso de Bartenieff permite-nos vislumbrar que a espinha dorsal do seu método, seus princípios e conceitos básicos nascem da tessitura de suas múltiplas experiências na área de estudos do movimento humano: como bailarina e coreógrafa, fisioterapeuta e massagista, analista do movimento, pesquisadora dos aspectos neurocinesiológicos do movimento, precursora da dançaterapia e investigadora das teorias de movimento do grande mestre da dança Rudolf Laban. Mas, acima de tudo, seus materiais resultam dos questionamentos e preocupações que a impulsionaram a desenvolver suas ideias e conduzir suas descobertas. Podemos dizer que são frutos da união entre seu processo de vida, o contexto sociocultural em que cresceu, as percepções que a instigaram, os objetivos a que se propôs e os procedimentos que desenvolveu para atingi-los.

Como foi ressaltado, Bartenieff dividiu com Laban o fascínio pela ação corporal do sujeito no meio ambiente e o interesse em fazer crescer potencialidades espaciais e dinâmicas do movimento. No entanto, para se garantir o desenvolvimento e o uso eficiente dessa inteligência expressiva, observou que era necessário investir no polo complementar desse fenômeno, na 
percepção e na consciência dos suportes internos, uma vez que sensações proprioceptivas e musculares, alinhamento ósseo, clareza cinética são fundamentais para se sustentar o movimento que viaja para o espaço e que se recria ao compor-se com o outro, pelo exercício da alteridade.

"Apoio precede o movimento" e "antes de fazer é preciso permitir"13 são frases de Bartenieff que serão o fio condutor de seu trabalho, apontando para a ideia de que, antes que se possa estabelecer eficiência na interação com o espaço externo, é preciso desenvolver uma profundidade interior. Sua proposta para a conquista de conectividade, fluência e integração será construída pela reafirmação do que é intrínseco ao organismo humano. Focará sua atenção, portanto, nas raízes do desenvolvimento perceptivo-motor, no contato com a força evolucionária de conhecimento e sensibilidade humana, com o intuito de abrir caminhos para que aflore uma herança motora motivadora do processo de mobilidade.

Podemos afirmar que esse pensamento está de acordo com as novas pesquisas em neurociências do século XX. Tal conhecimento aponta que, no âmbito neurofisiológico, permitir o aflorar de uma sabedoria própria do corpo em movimento refere-se ao encontro de uma nova afinação na relação corpo/ mente, que se inicia no contato com os centros mais primitivos de resposta e percepção. Mover-se inclui um âmbito de aprendizagem também reflexivo, que resgata conhecimentos pré-conscientes, desenvolvidos por meio de uma memória coletiva implícita. Esse saber, arraigado à matéria do corpo, forma uma base para a realização das ações regidas pelos centros mais altos de controle do movimento ${ }^{14}$.

Neste sentido, o enfoque dos Fundamentos estará no reconhecimento e na vivência de atividades básicas que dão suporte aos processos mais complexos de ações e criatividade, como, por exemplo: sentir o movimento de processos orgânicos, a respiração, os fluxos, as formas e texturas dos tecidos e os sistemas do corpo; perceber e exercitar a transferência de peso em mudanças posturais da posição deitada para a sentada e em pé, valorizando a experiência do contato ativo com o chão nos processos de rolar, arrastar-se, engatinhar, antes de mover-se nos níveis mais altos do espaço; ou, ainda, entregar-se à intuição ao dançar, como ocorre na dança-contato, uma experiência de contínua escuta e acolhimento do inesperado. Seu objetivo era facilitar o equilíbrio entre os vários níveis de funcionamento do corpo, bem como possibilitar a criação de um network neuro-sensório-motor tridimensional, gerador de ações expressivas integrativas e de espessuras multifacetada.

Bartenieff, levando em conta o trabalho de Laban, elaborou sua visão do movimento incluindo também uma análise da
13.

Frases como essas são repassadas pelos discípulos de Bartenieff como contribuições preciosas de seus ensinamentos. As frases citadas acima foram mencionadas nos três programas de formação nos quais participei: em 1994-1996, como aluna, e em 1996-1998 e 2006, como professora assistente.

14

Bartenieff, refere-se a três regiões do cérebro como centros organizadores de diferentes aspectos do movimento. $\mathrm{O}$ cérebro baixo, incluindo a medula espinhal e o cerebelo, coordena ações ligadas à sobrevivência, ações que realizamos sem pensar: andar, falar, cair, mastigar, engolir, dormir. É também o principal responsável pelo desdobramento dos Padrões Neurocinesiológicos Básicos. O cérebro médio, incluindo o tálamo e hipotálamo, é o centro emocional primitivo, que responde a uma sabedoria sentida, não categorizada, e percebe tridimensionalmente 0 espaço pelo aparato do ouvido interno. O cérebro alto, composto pelo córtex frontal, é um centro organizador dos processos mais complexos, conscientes e criativos. Relaciona-se com o uso das mãos, visão e ação do corpo no espaço (BARTENIEFF, 1977). Segundo ela é preciso estimular o funcionamento conjunto desses três níveis, para que o resultado expressivo do movimento seja pleno, ou seja, integre os processos do corpo e da mente. 
realidade sociocultural de seu tempo. Abordou questões que acredito serem ainda pertinentes nos dias de hoje. Uma das percepções propulsoras de seus fundamentos, conforme argumentação desse artigo, atentou para a problemática da separação corpo, mente, emoção e espírito, que, em sua observação, surgia no corpo como quebra do contínuo interno/externo, sensorial/físico, corpo/espaço, singular/coletivo, induzindo a desconexão de uma mobilidade corporal global. Neste caso, era possível observar no corpo uma organização em partes, como ocorre em um fazer mecânico, agindo sem o apoio das diversas camadas de conectividade. Esse uso isolado das partes tornava-se aparente, por exemplo, na descontinuidade de movimento entre a unidade inferior do corpo - bacia, pernas e pés - e a unidade superior - tórax, braços e cabeça, ou na relação entre centre, meio-membros e extremidades.

Trabalhar a separação superior/inferior era de primeira importância para Irmgard, assim como era a redescoberta do centro de gravidade, o aterramento, e colocar o corpo (todo) em movimento. É por isto que existe uma ênfase no seu trabalho em exercícios para a parte inferior do corpo e para a conectividade superior/inferior através da repadronização principalmente do movimento cruzado (HACKNEY, 1998, p. 7).

De acordo com seu ponto de vista, em uma sociedade orientada para realizações de ordem intelectual e material - em que a ênfase estava no desejo de conquistar o mundo e o foco colocado, não na vivência do acontecimento presente, mas projetado para a formalização de um produto futuro -, evidenciava-se no corpo um tipo de função de mobilidade de extensão para o fora, frequentemente sem o suporte das funções de pressão ou contato com o solo - ambas funções básicas que apoiam o sequenciamento processual eficiente do movimento. Ao se guiar por uma ação centrada no desenvolvimento de ideias e pensamentos, organizada pelo uso excessivo do potencial cognitivo (centro alto de controle do cérebro), o sujeito apresentava, na construção da sua corporeidade, uma tendência em minimizar a estimulação dos processos mais pré-conscientes do movimento, responsáveis, como já vimos, por criar uma base e oferecer uma profundidade enredada ao corpo para ações de maior complexidade.

A consequência dessa forma de agir resulta em um movimento sem fundamentação, sem uma sequência de apoio que una princípios de dentro com intenções de fora. Quando esse contínuo de interdependência sujeito/meio não acontece, o movimento apresenta-se empobrecido, com carência de encadeamento e amplitude, no qual se percebe a falta de peso, força, riqueza de formas e enlace eu/outro, registrando a ausência de conectividade entre as várias instâncias do ser. 
Para atuar nesse contexto, trazendo uma visão equilibradora, Bartenieff procurou criar uma ponte eficaz entre a incorporação dos processos orgânicos do corpo e sua expressividade exteriorizada. Seus conceitos, estabelecidos por meio de uma prática sensível e somática, buscam a redescoberta de um sequenciamento interior/exterior, e o engajamento total do indivíduo, em evolução, com a intenção de expressar-se no espaço, funcionando em afinidade e diálogo, e em um fluxo contínuo de ir e vir, entre si próprio e o mundo.

Considerações finais

Atualmente, muitos são os criadores, educadores corporais e teóricos da cena ${ }^{15}$ a ressaltar, como Bartenieff, que a corporeidade do artista cênico se constitui e aprofunda na intersecção entre a percepção sutil do espaço singular do sujeito e o reconhecimento do contexto coletivo, geográfico, sociocultural e político no qual ele se insere. Laurence Louppe (2004), teorizadora da dança, aproxima mais esse pensamento dessa área de conhecimento, ao considerar que a fonte da dança contemporânea expressa e integra as forças do mundo de hoje, sempre móveis e em estado de ressignificação. Uma dança que produz-se entre sujeito e entorno, nesse lugar de tensões e contra-tensões, de vazios criativos e possibilidades de formulação de movimento,

[...] onde o corpo assume ser material em fluxo, capaz de aprofundar, em seus tecidos, a compreensão de diferentes realidades. Quando em movimento dançante esse corpo, inserido no contexto, responde estética e ideologicamente às motivações, questionamentos e senso de prioridade presentes em seu tempo (LAMBERT, 2012, p. 41).

Em outras palavras, ao reconhecer a sua origem no espaço entre o fora e o dentro, a dança contemporânea abraça os processos neurológicos, sensoriais, orgânicos e afetivos como elementos construtores da linguagem móvel do corpo no espaço, alargando a compreensão da vivência criativa pela comunhão com o ressoar dos ritmos da interioridade. Apodera-se do sensível e do imaginário, por um processo de alquimia cinética único a cada indivíduo, possibilitando o suscitar de tantos corpos poéticos singulares e a construção de uma experiência dançada com sabor de invenção própria (SUQUET, 2008).

Simultaneamente, essa mesma dança abre seu campo de reflexões para os movimentos do externo, promovendo indagações sobre os modelos pré-determinados de expressão, posicionando-se de forma mais ética e política diante do conjunto de sistemas que estruturam o coletivo, despertando sua escuta
15. Laurence LOUPPE, 2004; José GIL, 2005; Annie SUQUET, 2008; Hubert GODARD, 2006; Klauss VIANNA, 1990, para citar alguns. 
para as diversidades, as instabilidades, o imprevisível. Frente a liberdade de investigação e de escolha, o artista se vê impulsionado a engajar-se criativamente no mundo, a buscar coerência e clareza por ações de maior autonomia, entregando-se a um contato com o movimento menos reducionista e mais integrado ao meio, crítica e conscientemente.

Concluindo, o trabalho desenvolvido por Bartenieff oferece procedimentos que apoioam o trilhar desse caminho sutil de leitura de si e participação no mundo, no qual sujeito, arte e contexto encontram-se em contínua reorganização. Media o aprendizado de acordos entre as expressões de fenômenos que se atam em um todo (interno/externo, singular/coletivo, corpo/ espaço), potencializando a manutenção do fluxo no movimento incessante da banda de moebios. Seu legado transita entre as dimensões da transcendência e do enraizamento. 


\section{REFERÊNCIAS}

BARTENIEFF, Irmgard. Notes from a course in correctives. New York: Dance Notation Breau Press, 1977.

BARTENIEFF, Irmgard; LEWIS, Doris. Body Movement: Coping with the Environment. Langhorne: Gordon \& Breach Science Publishers, 1980.

FEARS, E. W.; GOLDMAN, Ellen; HACKNEY, Peggy; REED, Virginia; SIEGEL, Marcia B.; Remembering Irmgard. In: Movemnt News, Laban/Bartenieff Institute of Movement Studies, v. 28, n. 2, p. 8-9, fall 2003.

HACKNEY, Peggy. Making connections: total body integration through Bartenieff fundamentals. Amsterdam: Gordon and Breach Publishers, 1998.

LAMBERT, Marisa. M. Expressividade Cênica pelo Fluxo Percepção/Ação: o Sistema Laban/Bartenieff para o desenvolvimento somático e a criação em dança. 2010. Tese (Doutorado em Artes) - Programa de Pós-Graduação em Artes da Cena, Universidade Estadual de Campinas, Campinas, 2010.

LAMBERT, Marisa. M. Fomento a Dança: Panorama de uma Experiência Múltipla. In: Fomento à Dança, 5 anos. Secretaria Municipal de Cultura, São Paulo: Secretaria Municipal de Cultura, 2012

LOUPPE, Laurence. Poétique de la danse contemporaine. Bruxelles: Contredanse, 2004.

SIEGEL, Marcia B. Profile: Irmgard Bartenieff. In: The Kinesis Report, v.2, n.4, 01-16, Summer 1980.

SUQUET, Annie. Cenas. O corpo dançante: um laboratório da percepção. In: COURTINE, Jean-Jacques (Dir.). História do Corpo, vol. 3: As mutações do olhar. O século XX. Petrópolis: editora Vozes, 2008. p. 509- 539.

RUBENFELD, Ilana. Irmgard Bartenieff. In: Somatics, California, 9-13, Autumn 1977. 